https://doi.org/10.30910/turkjans.515345

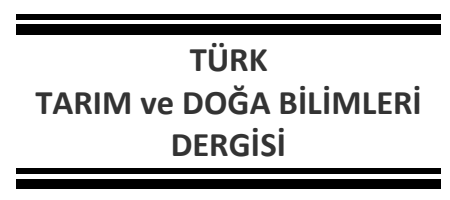

\title{
Endüstriyel Yoğurt Kültürleri İle Üretilen Maraş Tarhanasındaki Uçucu Aroma Maddelerinin Belirlenmesi $^{\&}$
}

\author{
Üzeyir DAĞ, Ahmet Levent iNANÇ*
}

Kahramanmaraş Sütçü İmam Üniversitesi, Fen Bilimleri Enstitüsü, Biyomüh. ve Bil. ABD, Kahramanmaraş, Türkiye

*Sorumlu yazar: linanc@ksu.edu.tr

Geliş Tarihi: 01.11.2018

Düzeltme Geliş Tarihi: 14.12.2018

Kabul Tarihi: 16.12 .2018

\section{Özet}

Son yıllarda geleneksel gıdaların endüstriyel üretimi yaygınlaşmaktadır. Tarhana da bunlardan biridir. Bu çalışmada üç farklı saf yoğurt kültüründen (Chr Hansen yogurt kültürleri; YC-380, CH-1 ve YF-L903) üç farklı konsantrasyon (önerilen kültür miktarlarının 3, 6 ve 9 katı; $\mathrm{mg} \mathrm{L}^{-1}$ ) kullanılarak yapılan yoğurtlardan maraş tarhanası üretimi gerçekleştirilmiş, tarhana örneklerindeki uçucu madde çeşit ve miktarlarının belirlenmesi amaçlanmıştır. Bir kültürün üç farklı konsantrasyonu ve üç farklı kültürün aynı konsantrasyonları arasındaki farklar istatiksel olarak değerlendirilmiştir. Örneklerde toplam 16 tane aldehit grubu, 11 tane keton grubu, 9 tane alkan grubu, 7 tane asit grubu, 3 tane ester grubu, 8 tane alkol grubu, 3 tane terpen grubu ve 12 adet diğer bileşiklerin varlığı tespit edilmiştir. 4-pentenal (\%0.27), 3-metil-2-bütanon (\%0.3), pent-3-en-2-on (\%0.06), heptan-2-on (\%5.08), propiyonik asit (\%0.79), bütil asetat (\%2.63), 2,3-bütadiol (\%1.71), 1-bütanol (\%0.56), simen $(\% 0.11)$ ve $p$-dikloro benzen $(\% 0.50)$ oranında sadece birer tarhana örneklerinde varlığı tespit edilmiştir. Aldehit grubuna dahil olan furfural bileşiğinin miktarı diğer bileşiklerle karşılaştırıldığında en yüksek yüzde alana sahip olmuştur. Örneklerdeki furfural bileşiğinin miktarının \%13.76-43.40 aralığında değiştiği belirlenmiştir. Tarhanalarda ortak uçucu bileşenlerin yanında her kültürle üretilen tarhanalarda farklı uçucu bileşenlerin bulunduğu belirlenmiştir. Sonuç olarak tüketicinin isteğine bağlı ürünlerin üretilmesi mümkün görülmektedir.

Anahtar kelimeler: Maraş tarhanası, uçucu madde, yoğurt kültürü.

\section{Determination of Volatile Aroma Substances in Maraş Tarhana Produced By Industrial Yoghurt Cultures}

\begin{abstract}
In recent years, traditional foods have been transformed into industrial production. Tarhana is one of them, too. In this study, tarhana production was performed from yogurts which were made by using three different concentrations ( 3,6 and 9 times the recommended amounts of cultures; $\mathrm{mg} \mathrm{L}^{-1}$ ) of three different pure yogurt cultures (Chr Hansen yogurt cultures; YC-380, CH-1 ve YF-L903), and it was aimed to determine the types and amounts of volatile substances in the tarhana samples. Differences between three different concentrations of one culture and the same concentrations of three different cultures were statistically evaluated. A total of 16 aldehyde groups, 11 ketone groups, 9 alkane groups, 7 acid groups, 3 ester groups, 8 alcohol groups, 3 terpene groups and 12 other compounds were determined in the samples. In only one of tarhana samples, 4-pentenal $(0.27 \%)$, 3-methyl-2-butanone (0.3\%), pent-3-ene-2-one $(0.06 \%)$, heptane-2-one $(5.08 \%)$, propionic acid $(0.79 \%)$, butyl acetate (2.63\%), 2,3-butadiol (1.71\%), 1-butanol (0.56\%), cymen (0.11\%) and p-dichloro benzene $(0.50 \%)$ were detected. The amount of furfural compound included in the aldehyde group had the highest percentage area compared to the other compounds. The amount of furfural compound in the samples varied between 13.76$43.40 \%$. In addition to the common volatile constituents in the tarhana, it was determined that there were different volatile components in the tarhana produced with each culture. As a result, it is possible to produce products based on consumer preference.
\end{abstract}

Key words: Maras tarhana, volatile compound, yogurt culture. 


\section{Giriş}

Yöresel özellik taşıyan tarhana, ülkemize ait bir fermente gıda maddesidir. Bölgeden bölgeye değişiklik gösteren tarhana çeşitlerinin bileşimleri, üretim şekilleri ve tüketim biçimleri farklıdır. Maraş tarhanası da kendine has özellikleri ile diğer tarhana çeşitlerinden ayrılmaktadır. Temel bileşeni dövme (yarma) ve yoğurt olan Maraş tarhanasının üretimi oldukça zaman alan ve zor bir süreçtir (Şekkeli ve ark., 2015). Üretim esnasında yoğurttaki laktik asit bakterileri ve buğdaydaki mayaların birlikte faaliyetleri sonucu gerçekleşen laktik asit ve alkol fermantasyonu tarhananın kendine özgü aroma ve lezzetin ortaya çıkmasında etkili olmaktadır (Gök ve ark., 2017).

Maraş tarhanası, üretimindeki farklı uygulamalar, bileşimindeki doğal katkılar ve farklı tüketilme alışkanlıkları ile lezzeti bakımından bilinen diğer tarhanalardan farklılaşmaktadır. Bu özellikleri nedeniyle 2010 yılı itibariyle Türk Patent Enstitüsü tarafından "coğrafi işaretli ürünler" kapsamında tescillendirilmiştir. Maraş tarhanasının tüketim şekilleri şöyle sıralanabilir; tarhana tam kurumadan yarı kurumuş (firik) halinde, kurumuş halde ve çerez gibi yenerek, çorba halinde, sıcak haldeki et veya kelle suyuna ıslanarak, yağda kızartılarak, ıslanmış tarhana yağda soğanla kavrularak veya sıcak sac ya da mangal üzerinde gevretilerek. Maraş tarhanasındaki ana bileşenler yoğurt ve buğday yarmasıdır (dövme). Genel olarak yarma/yoğurt oranı 1:1 veya 1:1.5 şeklindedir. Diğer bileşenlerin oranı ise, her $100 \mathrm{~kg}$ buğday dövmesine $\% 1$ tuz, \%0.5 kekik ve \%0.1 çörek otu şeklindedir (Özer, 2009; Coşkun, 2014; Şekkeli ve ark. 2015; Gök ve ark., 2017).

Eskiden geleneksel olarak evlerde üretiliyor iken günümüzde büyük çoğunluğu fabrika üretimidir. Fabrikasyon üretiminde fermente ürünlerin güvenli olmasının yanında zengin besleyici nitelikleri, tad ve aromaları da tüketilmelerini teşvik etmektedir (Dağlıoğlu ve ark., 2002; Erbaş ve ark., 2004). Başka bir ifadeyle bir gıda pazarda başarıyı elde etmek için, besleyici özelliklerinin yanı sıra sağlıklı ve lezzetli olmak zorundadır. Hijyen faktörü öne alınmasına rağmen ürünün pazar payını artıran onun lezzet ve aromasıdır (McGee, 2003). Bundan dolayı, gıda sanayisi için uçucu organik bileşiklerin belirlenmesi önem kazanmıştır. Protein, yağ ve karbonhidrat gibi temel bileşenlerin yanında uçucu ve uçucu olmayan aroma maddeleri de içeren gıdalar, karmaşık çok bileşenli matrikslerdir. Aroma bileşikleri, normal oda koşullarında gaz fazında bulunan, burun boşluğundaki koku alma dokusuna (olfaktor reseptörlerine) ulaşarak algılanan uçucu moleküller olarak tanımlanırlar. Aroma bileşenlerinin, gıda maddesinden gaz fazına geçişleri, gıda matriksinde bulunan uçucu olmayan bileşiklerle olan etkileşim ile de ilgilidir (Eker ve Cabaroğlu, 2018). Aroma maddeleri kavramı, tat maddeleri kavramı gibi, daha esnek bir şekilde kullanılmalıdır, çünkü bir bileşim tipik olarak bir yiyeceğin kokusuna veya tadına olumlu katkıda bulunabilirken, başka bir gıdada hatalı bir kokuya veya tada ya da her ikisine birden sebep olabilir. Gıdada bulunan uçucu madde miktarı oldukça düşüktür (yaklaşık 10-15 mg kg-1). Bununla birlikte, genel olarak, çok sayıda bileşen içerirler. Özellikle, termal işlemlerle yapılan özel gıdalar (örneğin kahve), veya bir fermantasyon işlemiyle (örneğin tarhana, ekmek, bira, kakao veya çay) kombinasyon halindeyken, 800'den fazla uçucu bileşik içerir. Meyve ve sebzelerde de çok çeşitli bileşikler bulunmaktadır (Belitz ve ark., 2009). Nijssen ve ark., (1999) bilinen tüm uçucu bileşikleri gıdalara ve bileşik sınıflarına göre sınıflandırmışlar ve bir tablo halinde derlenmiş olarak yayınlamışlardır. Bu derlemede 450'den fazla gidada toplam 7100 bileşen listelenmekte olup, bu da internette (Leffingwell, 2018) bir veri tabanı olarak mevcuttur (Nijssen ve ark., 2016).

Maraş tarhanası üretiminin geleneksel üretimden endüstriyel üretime dönüşmesinden dolayı farklı endüstriyel yoğurt kültürleri ve bu kültürlerin farklı konsantrasyonlarda kullanımı ile üretilen yoğurtların Maraş tarhanasının uçucu aromatik bileşenleri üzerine etkileri çalışmanın amacını oluşturmuştur.

\section{Materyal ve Yöntem Materyal}

Tam yağlı süt (Ülker A.Ş.) ve süt kreması marketten satın alınmıştır. Yoğurt kültürleri (Streptococcus thermophilus and Lactobacillus bulgaricus karşımını içeren YC-380, CH-1 ve YF-L903 kültür çeşitleri;) Chr Hansen (İstanbul) firmasından satın alınmıştır. Yağsız süt tozu Pınar A.Ş. (İzmir)' den temin edilmiştir. Dövme (yarma; Elbistan yazlığı olarak adlandırılan buğdaydan yapılmış) Kahramanmaraş'taki yerel bir değirmenden temin edilmiştir.

\section{Yöntem}

Maraş tarhanasının üretimi Şekil 1'de gösterildiği gibi gerçekleştirilmiştir. 
Sütün standardizasyonu

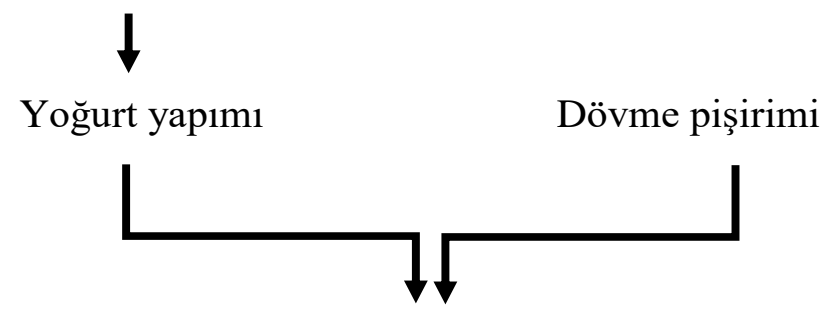

Tarhana hamuru

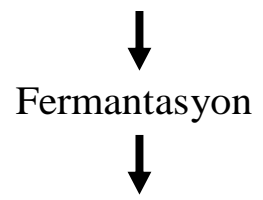

Sergiye serim

Kurutma

Maraş tarhanası

Şekil 1. Maraş tarhanasının deneysel üretim şeması

Sütün standardize edilmesi: Süt laboratuvar ortamında standardize ve sterilize edilmiştir. Sütler, süt tozu ile kuru maddesi $\% 15(\mathrm{w} / \mathrm{w})^{\prime}$ e, süt kreması ile yağ miktarı \%3 (w/w)'e ayarlanmış ve $121^{\circ} \mathrm{C}$ sıcaklıkta $3 \mathrm{dk}$. ısıl işleme tabi tutulmuştur.

Yoğurt yapımı: Standardize edilen ve $44^{\circ} \mathrm{C}$ sıcaklığa getirilmiş sütlerin $100^{\prime} \mathrm{er} \mathrm{mL'si} \mathrm{ile} \mathrm{yoğurt} \mathrm{kültürleri}$ karıştırılmış ve 2 saat inkübasyona tabi tutularak önaşılama işlemi gerçekleştirilmiştir. Aşılanmış sütler ile $44{ }^{\circ} \mathrm{C}$ sıcaklıktaki sütlere ilave edilerek 4 saat fermantasyona bırakılmıştır. Daha sonra yoğurtlar 1 gün buzdolabında $\left(4^{\circ} \mathrm{C}\right)$ bekletilerek olgunlaştırma işlemi yapılmıştır. Firmanın her bir kültür için tavsiye ettiği kültür miktarının 3, 6 ve 9 katı alınarak konsantrasyonlar ( $\mathrm{mg} \mathrm{L}^{-1}$ ) hazırlanmıştır. YC-380 (Y1) için tavsiye edilen kültür miktarı $15.84 \mathrm{mgL}^{-1}$, $\mathrm{CH}-1$ (Y2) için $88 \mathrm{mgL}^{-1}$ ve YF-L903 (Y3) için $60 \mathrm{mg} \mathrm{L}^{-}$ ${ }^{1}$ dir. Örneklerin kodlanması; örneğin $Y 1$ yoğurdu için sırasıyla Y1-3, Y1-6 ve Y1-9 şeklinde yapılmıştır. Toplamda 3 farklı yoğurt kültüründen 3 farklı konsantrasyonda 9 adet yoğurt üretilmiştir.

Dövmenin (yarma) pişirilmesi: Dövmeler normal çeşme suyu ile yıkama işlemi yapıldıktan sonra yaklaşık hacimce 1 birim dövme 3 birim su olacak şekilde pişirme kabına konularak ocakta pişirilmiştir.
Pişirme işlemine dövme içerisinde beyaz nokta kalmayıncaya kadar devam edilmiştir.

Maraş tarhanası ve hamurunun yapımı: Pişmiş dövmeler $44{ }^{\circ} \mathrm{C}$ sıcaklığa getirilmiş, ağırlıkça 1 birim dövme 2,5 birim yoğurt olacak şekilde karıştırılarak tarhana hamurları elde edilmiştir. Daha sonra mikserde homojenize edilmiştir. Tarhana hamurlarına 8 saat süreyle fermantasyon işlemi gerçekleştirilmiştir. Fermantasyondan sonra tarhana hamurları $65{ }^{\circ} \mathrm{C}$ sıcaklıkta, su içeriği \%10 (w/w) oluncaya kadar, etüvde kurutulmuştur. Y1, Y2 ve $Y 3$ yoğurtlarından oluşturulan tarhana hamurları sırasıyla $\mathrm{H} 1, \mathrm{H} 2$ ve $\mathrm{H} 3$; bu hamurlardan üretilen tarhanalar T1, T2 ve T3 olarak, konsantrasyonlar ise örneğin T1 için T1-3, T1-6 ve T1-9 olarak kodlanmıştır. Toplamda 9 adet tarhana örneği olmuştur.

Tepe boşluğu analizi: Tarhana örneklerinde uçucu bileşen tayini, Ligor ve ark. (2004) tarafından belirlenen metoda göre yapılmıştır. Uçucu aroma bileşenleri analizi için yapılan ön denemeler doğrultusunda örnekler 15 ml'lik viallere alınarak ağzı sızdırmaz teflon kapakla kapatılmıştır. Örnekler $70{ }^{\circ} \mathrm{C}$ ' de fibersiz 15 dakika bekletilip dengeye 
gelmesi sağlanmıştır. Daha sonra katı faz mikroekstraksiyon için uygun fiber (adsorbant olarak karboksen/polidimetil siloksan (CAR/PDMS)) viale daldırılmış ve 45 dakika süre ile tepe boşluğundaki uçucu bileşenleri adsorbe edilmiştir. En son fiber, gaz kromatografi cihazının enjeksiyon portunda bekletilerek, yakalanan uçucu bileşenleri desorbe ederek GC-MS sistemi kolonuna gönderilmiştir. Uçucu aroma bileşenleri analizinde Shimadzu GC/MS-QP2010 SE dedektör donanımlı Shimadzu (Japan) GC-2010 Plus gaz kromatografi cihazı kullanılmıştır. Analizlerde Restek Rx-5Sil MS $30 \mathrm{~m} * 0.25 \mathrm{~mm}, 0.25 \mu \mathrm{m}$ kolon kullanıımıştır. Çalışma koşulları şu şekilde oluşturulmuştur; Enjeksiyon bloğu sıcaklığı: $250^{\circ} \mathrm{C}$, Dedektör sıcaklığı: $250^{\circ} \mathrm{C}$, Taşıyıcı gaz: Helyum, Akış Hızı $\left(\mathrm{ml} \mathrm{dk}^{-1}\right)$ : 1,61, Enjeksiyon modu: Split, Dedektör: $70 \mathrm{eV}$, İyonlaştırma Türü: El, Sıcaklık Programı: $40^{\circ} \mathrm{C}^{\prime}$ de 2 dakika bekledikten sonra $250^{\circ} \mathrm{C}^{\prime}$ ye dakikada $4^{\circ} \mathrm{C}^{\prime}$ lik artışla ulaşmıştır. $250^{\circ} \mathrm{C}^{\prime}$ de 5 dakika bekletilmiştir. GC-MS analizleri yapılan bileşenlerin kütle spektrumları hem alıkonma süreleri hem de kütle spektrumlarından yararlanılarak yüzde alan (\% alan) tanımlaması yapılmıştır.

istatiksel analizler: Araştırmada, örneklerinin analizleri 3 tekerrürlü olarak yapılmıştır. Elde edilen veriler, IBM (SPSS statistics 23) paket programı ile üç yönlü varyans analizine tabi tutulmuş ve önemli olan farklılıklar, ikili karşılaştırmalar bağımsız "Student" T-testi ile, çoklu karşılaştırmalar ise Duncan çoklu karşılaştırma testi ile \%5 önem seviyesinde belirlenmiştir $(p<0.05)$.

\section{Bulgular ve Tartışma}

Tepe boşluğu analizi ile tarhana örneklerinde toplam 69 adet uçucu aroma bileşiği belirlenmiştir. $\mathrm{Bu}$ bileşikler kimyasal yapılarına göre sınıflandırılmıştır. Aldehit, alkan, alkol, asit, ester, keton, terpen ve diğerleri şeklinde gruplara ayrılmıştır. Analiz metoduna göre belirlenen toplam yüzde alan içinde aldehit grubu \%23.2'sini, keton grubu \%15.9'ünü, alkan grubu \% 13.0'ını, asit grubu \% 10.1'ini, ester grubu \%4.3'ünü, alkol grubu \% 11.6'sını, terpen grubu \%4.3'ünü ve diğerleri \%17.4'ünü kapsamıştır. Örneklerde en fazla bulunan kimyasal grup aldehit grubu olmuştur. Tablo 1.'de örneklerde tespit edilen aldehit grubu bileşiklerin listesi, miktarları (\% alan) ve istatistiksel sonuçları verilmiştir. Asetaldehit sadece T3-3'de ve (E,E)-2,4-dekadienal ise sadece T1-3'de tespit edilememiştir. 4-pentenal sadece T1-3'de tespit edilirken diğer örneklerde tespit edilmemiştir. 3metil bütanal, heksanal, furfural, benzaldehit, nonanal ve dekanal bileşikleri bütün örneklerde görülmüştür. T2 örneklerinin tamamında izobütanal, 4-pentenal, (Z)-2-heptenal, benzen asetaldehit ve (E)-okt-2-enal bileşiklerine, T3 örneklerinde 4-pentenal, oktanal, (E)-okt-2-enal ve dekanal bileşiklerine hiç rastlanılmamıştır. Furfural yüzde alan miktarı olarak en yüksek (\%37.53-43.40) T3 örneklerinde bulunmuş ve istatiksel karşılaştırmada fark gözlenmemiştir ( $p>0.05)$. Diğer tarhana örneklerinde de en fazla bulunan aldehit grubu bileşik furfural olmuştur. Tablo 2.'de örneklerde tespit edilen keton grubu bileşiklerin listesi, miktarları (\% alan) ve istatistiksel sonuçları gösterilmiştir. 2-propanon ve 1-fenil etanon sadece T3-3 örneğinde tespit edilememiştir. Bununla birlikte, 3-metil-2-bütanon, pent-3-en-2-on ve heptan-2-on bileşikleri sırasıyla sadece T1-9, T3-9 ve T3-6 örneklerinden bulunmuştur. Bu yüzden istatiksel analizleri yapılmamıştır. Ayrıca 2tridekanon sadece T1-6'da ve T3-9'da bulunduğu için T1 ve T3 örneklerinin kendi konsantrasyonları arasında, 3 ve 9 konsantrasyonlarda üretilen diğer tarhana örnekleri arasında karşılaştırma yapılmamıştır. 2-nonanon ve nonil metil keton örneklerde ortak keton bileşikleri olarak belirlenmiştir. 2-nonanon en çok T1-6 ve T1-9 örneğinde bulunmuş ve aralarında istatiksel fark oluşmamıştır $(p>0.05)$. Nonil metil keton ise en yüksek T1-6 örneğinde bulunmuştur $(p<0.05)$. Alkan grubundan 2,4 dimetil heksan ile dekan bileşikleri T3 örneklerinin hiçbirinde tespit edilememiştir (Tablo 3). Heptan sadece T2-9 örneğinde, nonedekan ise sadece T3-6 örneğinde belirlenememiştir. Dodekan ve tridekanın tüm örneklerde ortak alkan grubu bileşikler olduğu görülmektedir. Fakat konsantrasyon artışı ile bu bileşikler doğrusal bir artış ve azalış göstermemişlerdir. Alkan grubu içerisinde yüzden alan olarak heptan, dodekan, tridekan bileşikleri hâkim olmuştur. Tridekan T2-3 örneğinde \% 10.65 bulunurken, heptan T1-3 örneğinde \%8.63 bulunmuştur. Asit ve ester grubu bileşikler bir tabloda toplanmıştır (Tablo 4). Asetik asit, oktanoik asit ve pelargonik asitin, T1-6 örneği hariç tarhanaların baskın uçucu organik asitleri olduğu belirlenmiştir. En düşük asetik asit miktarı (\% alan) T2-6 örneğinde \%3.76, en yüksek T3-3 örneğinde \% 11.5 olarak bulunmuştur. Oktanoik asit tüm örneklerde \%1.27-2.63 aralığında, pelargonik asit ise \%0.55-1.12 aralığında tespit edilmiştir. İzovalerik aside sadece T3-3 ve T3-6 örneklerinde rastlanılmıştır. Proponoik asit \% 0.79 seviyesinde sadece T3-9 tarhana örneğinde çıkmıştır. Laktik asit metil esteri, heksanoik asit bütil esteri ve bütil asetat olmak üzere üç adet ester grubu bileşik tespit edilmiştir. bütil asetat sadece T2-6 örneğinde bulunurken, T1 örneklerinde heksanoik asit bütil esteri ve T2 örneklerinde laktik asit metil esterinin bulunmadığı belirlenmiştir. 
Tablo 1. Örneklerdeki aldehit grubu bileşiklerin listesi, miktarları (\% alan) ve istatistiksel sonuçları*

\begin{tabular}{|c|c|c|c|c|c|c|c|c|c|}
\hline \multirow{2}{*}{ Bileşik } & \multicolumn{9}{|c|}{ Örnek } \\
\hline & T1-3 & T1-6 & T1-9 & T2-3 & T2-6 & T2-9 & T3-3 & T3-6 & T3-9 \\
\hline Asetaldehit & $0.47^{\mathrm{ax}}$ & $0.98^{\mathrm{cr}}$ & $0.69^{b}$ & $0.72^{\mathrm{bY}}$ & $0.53^{a x}$ & $0.65^{\text {ba }}$ & $\mathrm{TE}^{* *}$ & $0.73^{b x}$ & $0.46^{a}$ \\
\hline $\begin{array}{l}\text { İzobütanal } \\
\text { 3-metil bütanal }\end{array}$ & $\begin{array}{l}1.18^{\mathrm{b}} \\
7.02^{\mathrm{bY}}\end{array}$ & $\begin{array}{c}\text { TE } \\
2.35^{\mathrm{ax}}\end{array}$ & $\begin{array}{l}0.36^{a} \\
2.39^{a Y}\end{array}$ & $\begin{array}{c}\text { TE } \\
0.66^{\mathrm{ax}}\end{array}$ & $\begin{array}{c}\mathrm{TE} \\
1.97^{\mathrm{bx}}\end{array}$ & $\begin{array}{c}\text { TE } \\
0.72^{\mathrm{ax}}\end{array}$ & $\begin{array}{c}\text { TE } \\
0.87^{\mathrm{ax}}\end{array}$ & $\begin{array}{l}0.37 \\
2.03^{b x}\end{array}$ & $\begin{array}{c}\text { TE } \\
0.89^{a x}\end{array}$ \\
\hline 2-metil bütanal & $3.41^{b}$ & $1.09^{\mathrm{aY}}$ & $1.37^{\mathrm{aY}}$ & $\mathrm{TE}$ & $1.18^{\mathrm{aY}}$ & $1.21^{\mathrm{aY}}$ & $\mathrm{TE}$ & $0.71^{b x}$ & $0.33^{a x}$ \\
\hline 4-pentenal & 0.27 & $\mathrm{TE}$ & $\mathrm{TE}$ & TE & TE & TE & TE & TE & TE \\
\hline Heksanal & $8.75^{b Y}$ & $3.36^{\mathrm{ax}}$ & $3.13^{\mathrm{ax}}$ & $7.27^{\mathrm{aY}}$ & $11.03^{\mathrm{bY}}$ & $9.12^{a b Y}$ & $0.93^{\mathrm{ax}}$ & $1.63^{b x}$ & $4.15^{c x}$ \\
\hline Furfural & $13.76^{\mathrm{ax}}$ & $26.44^{\mathrm{bY}}$ & $35.04 \mathrm{cr}$ & $14.75^{\mathrm{ax}}$ & $15.46^{\mathrm{ax}}$ & $16.23^{a x}$ & $37.53^{\mathrm{aY}}$ & $43.40^{a z}$ & $41.59^{\mathrm{ar}}$ \\
\hline Heptanal & $1.17^{\mathrm{bx}}$ & $0.78^{a x}$ & $0.78^{\mathrm{ax}}$ & $1.7^{\mathrm{aY}}$ & $1.31^{\mathrm{aY}}$ & $1.78^{\mathrm{aY}}$ & TE & $1.56^{Y}$ & TE \\
\hline (Z)-2-heptenal & $0.35^{b}$ & $0.27^{\mathrm{aY}}$ & TE & $\mathrm{TE}$ & $\mathrm{TE}$ & $\mathrm{TE}$ & TE & $0.12^{x}$ & $\mathrm{TE}$ \\
\hline Benzaldehit & $3.20^{\mathrm{ax}}$ & $3.76^{\mathrm{ax}}$ & $3.82^{\mathrm{aXY}}$ & $4.46^{\mathrm{aby}}$ & $3.36^{\mathrm{ax}}$ & $4.65^{\mathrm{bY}}$ & $2.82^{\mathrm{ax}}$ & $3.96^{\mathrm{bx}}$ & $3.53^{a b x}$ \\
\hline Oktanal & $0.67^{\mathrm{ax}}$ & $0.97^{b x}$ & $0.75^{\mathrm{ax}}$ & $1.72^{\mathrm{cY}}$ & $0.83^{a x}$ & $1.33^{\mathrm{bY}}$ & $\mathrm{TE}$ & $\mathrm{TE}$ & $\mathrm{TE}$ \\
\hline Benzen asetaldehit & $0.81^{b x}$ & $1.02^{\mathrm{cY}}$ & $0.39^{a x}$ & TE & $\mathrm{TE}$ & TE & $0.97^{b x}$ & $0.79^{a b x}$ & $0.67^{\mathrm{aY}}$ \\
\hline (E)-okt-2-enal & $0.25^{\mathrm{a}}$ & $0.31^{\mathrm{a}}$ & TE & TE & TE & TE & TE & $\mathrm{TE}$ & TE \\
\hline Nonanal & $5.09^{b Y}$ & $7.05^{\mathrm{cr}}$ & $3.04^{\mathrm{ar}}$ & $4.27^{\mathrm{bY}}$ & $2.82^{\mathrm{ax}}$ & $3.81^{\mathrm{bz}}$ & $2.74^{\mathrm{bx}}$ & $2.38^{b x}$ & $1.61^{\mathrm{ax}}$ \\
\hline Dekanal & TE & $0.61^{b}$ & $0.37^{\mathrm{a}}$ & 0.5 & TE & TE & $\mathrm{TE}$ & TE & TE \\
\hline$(E, E)$-2,4-dekadienal & TE & $0.47^{\mathrm{aY}}$ & $0.65^{\mathrm{ax}}$ & $0.69^{b x}$ & $0.58^{\mathrm{abY}}$ & $0.48^{\mathrm{ax}}$ & $0.75^{b x}$ & $0.33^{\mathrm{ax}}$ & $1.01^{\mathrm{cY}}$ \\
\hline
\end{tabular}

* “a-c" serisi bir kültürün üç farklı konsantrasyonları ve "X-Z” serisi üç farklı kültürün aynı konsantrasyonları arasındaki istatiksel farkı göstermektedir ( $\mathrm{p}<0.05)$. ** TE: tespit edilemedi.

Tablo 2. Örneklerdeki keton grubu bileşiklerin listesi, miktarları (\% alan) ve istatistiksel sonuçları*

\begin{tabular}{|c|c|c|c|c|c|c|c|c|c|}
\hline \multirow{2}{*}{ Bileşik } & \multicolumn{9}{|c|}{ Örnek } \\
\hline & T1-3 & T1-6 & T1-9 & T2-3 & T2-6 & T2-9 & T3-3 & T3-6 & T3-9 \\
\hline 2-propanon & $1.28^{\mathrm{bY}}$ & $0.83^{\mathrm{ax}}$ & $0.83^{\mathrm{aY}}$ & $0.49^{\mathrm{aX}}$ & $1.56^{\mathrm{cY}}$ & $1.15^{\mathrm{bz}}$ & $\mathrm{TE} * *$ & $0.68^{\mathrm{bx}}$ & $0.34^{\mathrm{ax}}$ \\
\hline 2-pentanon & 0.40 & TE & TE & TE & $0.55^{\mathrm{ax}}$ & $0.61^{a}$ & $\mathrm{TE}$ & $0.63^{x}$ & TE \\
\hline 3-hidroksi-2-bütanon & $0.16^{\mathrm{ax}}$ & $0.29^{b x}$ & TE & $0.53^{\mathrm{aY}}$ & $0.69^{a b Y}$ & $0.73^{\text {by }}$ & $\mathrm{TE}$ & TE & $0.08^{x}$ \\
\hline 3-metil-2-bütanon & $\mathrm{TE}$ & TE & 0.3 & $\mathrm{TE}$ & TE & $\mathrm{TE}$ & TE & TE & TE \\
\hline 1-fenil etanon & $0.44^{\mathrm{ax}}$ & $1.27^{\mathrm{bY}}$ & $1.64^{\mathrm{cY}}$ & $0.68^{a Y}$ & $0.86^{\mathrm{ax}}$ & $0.69^{a x}$ & TE & $0.77^{\mathrm{ax}}$ & $0.65^{\mathrm{ax}}$ \\
\hline 2-nonanon & $0.87^{\mathrm{ax}}$ & $1.53^{b}$ & $1.37^{b}$ & $1.33^{\mathrm{aY}}$ & $1.04^{\mathrm{a}}$ & $1.27^{\mathrm{a}}$ & $0.96^{\mathrm{ax}}$ & $1.06^{\mathrm{a}}$ & $1.15^{\mathrm{a}}$ \\
\hline Nonil metil keton & $0.76^{\mathrm{aXY}}$ & $1.22^{\mathrm{bY}}$ & $0.79^{\mathrm{aY}}$ & $0.96^{\mathrm{aY}}$ & $0.87^{a x}$ & $0.86^{\mathrm{aY}}$ & $0.59^{a b x}$ & $0.71^{b x}$ & $0.5^{\mathrm{ax}}$ \\
\hline 2-tridekanon & TE & 0.31 & TE & $\mathrm{TE}$ & $\mathrm{TE}$ & TE & TE & TE & 0.28 \\
\hline Pent-3-en-2-on & $\mathrm{TE}$ & TE & $\mathrm{TE}$ & $\mathrm{TE}$ & $\mathrm{TE}$ & $\mathrm{TE}$ & $\mathrm{TE}$ & TE & 0.06 \\
\hline Heptan-2-on & $\mathrm{TE}$ & TE & $\mathrm{TE}$ & $\mathrm{TE}$ & TE & TE & TE & 5.08 & TE \\
\hline 6-Metil-5-hepten-2-on & $\mathrm{TE}$ & $\mathrm{TE}$ & $\mathrm{TE}$ & $\mathrm{TE}$ & $1.32^{Y}$ & $\mathrm{TE}$ & $0.44^{\mathrm{a}}$ & $0.85^{b x}$ & $\mathrm{TE}$ \\
\hline
\end{tabular}

* "a-c" serisi bir kültürün üç farklı konsantrasyonları ve "X-Z" serisi üç farklı kültürün aynı konsantrasyonları arasındaki istatiksel farkı göstermektedir ( $\mathrm{p}<0.05)$. ** TE: tespit edilemedi. 
Tablo 3. Örneklerdeki alkan grubu bileşiklerin listesi, miktarları (\% alan) ve istatistiksel sonuçları*

\begin{tabular}{|c|c|c|c|c|c|c|c|c|c|}
\hline \multirow{2}{*}{ Bileşik } & \multicolumn{9}{|c|}{ Örnek } \\
\hline & T1-3 & T1-6 & T1-9 & T2-3 & T2-6 & T2-9 & T3-3 & T3-6 & T3-9 \\
\hline 2,4 dimetil heksan & 2.26 & $\mathrm{TE}^{* *}$ & TE & $\mathrm{TE}$ & 2.14 & $\mathrm{TE}$ & TE & TE & $\mathrm{TE}$ \\
\hline Heptan & $8.63^{b z}$ & $2.17^{\mathrm{ax}}$ & $2.61^{\mathrm{aY}}$ & $5.20^{\mathrm{aY}}$ & $5.02^{\mathrm{ay}}$ & TE & $0.62^{a x}$ & $2.05^{c x}$ & $1.48^{b x}$ \\
\hline Dekan & $0.35^{a}$ & $0.39^{a x}$ & $0.72^{b}$ & TE & $0.60^{Y}$ & TE & TE & TE & TE \\
\hline Undekan & $0.64^{a x}$ & $1.05^{b}$ & $1.02^{b x}$ & $1.50^{z}$ & TE & TE & $1.10^{\mathrm{aY}}$ & TE & $0.98^{a x}$ \\
\hline Dodekan & $2.32^{\mathrm{ax}}$ & $5.05^{\mathrm{bY}}$ & $5.16^{b x}$ & $8.01^{c z}$ & $2.82^{\mathrm{ax}}$ & $5.33^{b x}$ & $5.22^{\mathrm{bY}}$ & $1.91^{\mathrm{ax}}$ & $4.84^{b x}$ \\
\hline Tridekan & $3.01^{\mathrm{ax}}$ & $8.41^{b Y}$ & $7.29^{b x}$ & $10.65^{c z}$ & $5.33^{a x}$ & $7.55^{b x}$ & $7.87^{\mathrm{bY}}$ & $3.95^{\mathrm{ax}}$ & $7.03^{b x}$ \\
\hline Heptadekan & $0.66^{\mathrm{aY}}$ & $0.47^{\mathrm{ax}}$ & TE & $0.70^{\mathrm{aY}}$ & $0.68^{a x}$ & $0.63^{a}$ & $0.42^{x}$ & TE & TE \\
\hline Nonedekan & $0.79^{b Y}$ & $0.82^{\mathrm{bx}}$ & $0.38^{a x}$ & $0.79^{\mathrm{ar}}$ & $0.66^{a x}$ & $0.65^{\mathrm{ay}}$ & $0.50^{\mathrm{ax}}$ & TE & $0.48^{a x}$ \\
\hline Tetradekan & TE & $0.47^{\mathrm{a}}$ & $0.32^{\mathrm{ax}}$ & TE & TE & TE & $0.52^{\mathrm{a}}$ & TE & $0.39^{a x}$ \\
\hline
\end{tabular}

* “a-c" serisi bir kültürün üç farklı konsantrasyonları ve "X-Z" serisi üç farklı kültürün aynı konsantrasyonları arasındaki istatiksel farkı göstermektedir ( $p<0.05$ ).

** TE: tespit edilemedi.

Tablo 4. Örneklerdeki asit-ester grubu bileşiklerin listesi, miktarları (\% alan) ve istatistiksel sonuçları

\begin{tabular}{|c|c|c|c|c|c|c|c|c|c|c|}
\hline \multirow{2}{*}{ 을 } & \multirow{2}{*}{ Bileşik } & \multicolumn{9}{|c|}{ Örnek } \\
\hline & & T1-3 & T1-6 & T1-9 & T2-3 & T2-6 & T2-9 & T3-3 & T3-6 & T3-9 \\
\hline \multirow{7}{*}{ 蒙 } & Asetik asit & $4.69^{a x}$ & $7.11^{b Y}$ & $6.07^{a b x}$ & $7.92^{\mathrm{bY}}$ & $3.76^{\mathrm{ax}}$ & $5.35^{\mathrm{ax}}$ & $11.5^{\mathrm{bz}}$ & $6.35^{\mathrm{aY}}$ & $5.24^{a x}$ \\
\hline & Heksanoik asit & TE & TE & $0.75^{x}$ & TE & $3.66^{b}$ & $1.38^{\mathrm{aY}}$ & TE & TE & TE \\
\hline & Oktanoik asit & $1.32^{\mathrm{ax}}$ & $\mathrm{TE}$ & $1.27^{\mathrm{ax}}$ & $1.64^{\mathrm{ax}}$ & $2.24 \mathrm{bx}$ & $1.97^{\mathrm{abY}}$ & $1.73^{a x}$ & $2.63^{\mathrm{bx}}$ & $2.33^{\mathrm{bY}}$ \\
\hline & Pelargonik asit & $1.01^{\mathrm{bY}}$ & $\mathrm{TE}$ & $0.55^{\mathrm{ax}}$ & $0.62^{a x}$ & $0.65^{a x}$ & $0.63^{\mathrm{aXY}}$ & $1.12^{\mathrm{bY}}$ & $1.06^{\mathrm{bY}}$ & $0.72^{\mathrm{aY}}$ \\
\hline & Dekanoik asit & $0.97^{b Y}$ & $0.34^{\mathrm{ax}}$ & TE & TE & $0.79^{Y}$ & $\mathrm{TE}$ & $0.63^{a x}$ & $\mathrm{TE}$ & $0.71^{a}$ \\
\hline & İzovalerik asit & $\mathrm{TE}$ & $\mathrm{TE}$ & $\mathrm{TE}$ & $\mathrm{TE}$ & TE & $\mathrm{TE}$ & $0.85^{b}$ & $0.49^{a}$ & TE \\
\hline & Propanoik asit & $\mathrm{TE}$ & TE & $\mathrm{TE}$ & $\mathrm{TE}$ & TE & TE & $\mathrm{TE}$ & $\mathrm{TE}$ & 0.79 \\
\hline \multirow{3}{*}{$\begin{array}{l}\stackrel{亠}{ \pm} \\
\text { 岀 }\end{array}$} & Laktik asit, metil ester & $\mathrm{TE}$ & $1.31^{b}$ & $0.84^{a}$ & TE & TE & TE & 2,61 & TE & TE \\
\hline & Heksanoik asit, bütil ester & TE & TE & TE & $1.13^{\mathrm{cY}}$ & $0.52^{\mathrm{a}}$ & $0.86^{b x}$ & $0.53^{a x}$ & TE & $0.64^{\mathrm{ax}}$ \\
\hline & Bütil asetat & TE & TE & TE & TE & 2.63 & TE & TE & $\mathrm{TE}$ & TE \\
\hline
\end{tabular}

* “a-c" serisi bir kültürün üç farklı konsantrasyonları ve "X-Z" serisi üç farklı kültürün aynı konsantrasyonları arasındaki istatiksel farkı göstermektedir ( $p<0.05$ ).

** TE: tespit edilemedi. 
Tablo 5, alkol ve terpen grubu bileşikleri listesini içermektedir. Tarhana örneklerinde toplamda sekiz adet alkol grubu bileşik tespit edilmiş ama T1 örneklerinde bunların dört tanesi (okten-3-ol, benzil alkol, 1-bütanol, heksanol) hiç bulunmamıştır. T2 örneklerin 2,3 bütadiol, benzen etanol ve benzil alkol bileşiklerine rastlanılmamıştır. Benzer şekilde T3 örneklerinde 2,3 bütadiol ile 1bütanol bileşikleri tespit edilmemiştir. Bütün tarhana örneklerinde bulunan alkol grubu bileşik furfuril alkol olmuştur. En yüksek furfuril alkol T19'da görülürken yine en düşük miktar T1 örnekleri içerisindeki T1-3'de görülmüştür. T1 örnekleri kendi içlerinde karşılaştırıldığında konsantrasyon arttıkça furfuril alkolün miktarı artmıştır $(p<0.05)$. 2,3 bütadiol T1-6 örneğinde, 1-bütanol sadece T2-3 örneğinde görülmektedir. Sayı olarak en az bileşik içeren grupların ikincisi olan terpen grubu da (diğeri ester grubu) üç adet bileşik içermektedir. Bunlardan simen sadece T3-9 örneğinde \%0.11 düzeyinde, karvakrol T1-3 ve T1-6 örneklerinde sırasıyla \%1.441.39 düzeyinde bulunmuştur. Limonen ise bütün örneklerde \%0.95-2.91 aralığında tespit edilmiştir. Tarhanalardaki uçucu bileşikler içerisinde diğer olarak gruplandırılan 12 adet bileşik bulunmuştur (Tablo 6). Tolüen ve 2-pentil furan tüm örneklerde görülürken T1 örneklerinde iki bileşiğin ( $p$-diklora benzen ve 3,5 dimetil fenol), T2 örneklerinde dört bileşiğin (dimetil disülfit, etil benzen, 3,5-di metil pirazin ve naftalin), T3 örneklerinde ise naftalin ve p-diklora benzen olmak üzere iki bileşiğin bulunmadığı belirlenmiştir.

Tarhana örneklerindeki uçucu bileşenlerin varlığı üç temel kaynağa dayandırılabilir. Birincisi hammadde, ikincisi tarhana hamurunun fermantasyonu ve sonuncusu kurutmadır. Hammadde olarak kullanılan yoğurt zaten çok karakteristik tat ve lezzet veren aroma bileşiklerini içermektedir. Aslında Maraş tarhanası üretiminde yoğurt yapım aşamasını birinci fermantasyon, hammaddelerin karıştırılıp tarhana hamurunun oluşturulması ve 8 saat bekletilmesini ise ikinci fermantasyon olarak düşünmek gerekir. Yoğurttan gelen uçucu bileşenleri etkileyen birçok faktör vardır. Yoğurdun tat ve aromasını yoğurt kültürleri (S. Thermophilus ve L. delbrueckeii subsp. Bulgaricus) tarafından sentezlenen laktik asit başta olmak üzere pirüvik, okzalik ve süksinik asit gibi uçucu olmayan asitler ile asetaldehit, aseton, diasetil gibi karbonil bileşenler vermektedir (Özer, 2006). Bu kültürler farklı metabolik yollar kullanarak karbonhidrat, protein ve nükleik asitlerden asetaldehit üretebilirler (Köse ve Ocak, 2014). Spesifik enzim aktiviteleri ile diğer birçok faktör de karbonil bileşenlerinin oluşumu üzerine etkilidir. Farklı sütlerle bile üretilen yoğurtlarda karbonil bileşenleri arasında fark olmaktadır (Erkaya ve
Şengül, 2008). Tarhananın diğer temel hammaddesi dövmedir. Dövme karakteristik olarak buğdayın özelliklerini gösterir. Çünkü, dövme; buğdayın hafif kabuğunun tıraşlanmış (değirmende buğday kepeğinin bir miktar alınması) halidir. Buğdaydaki temel gıda bileşeni karbonhidrat olan nişastadır. Tarhanaya da yapı kazandırmakla birlikte bünyesinde bazı aroma maddelerini bulundurmaktadır. Nişasta granüllerinde metanol, etanol, 1-propanol, 1-bütanol, propanoik asit, 1hekzanol, benzaldehit, dodekan, diasetil, ve etil asetat gibi uçucu bileşiklerin varlığı belirlenmiştir (Hau ve ark., 1996; BeMiller ve Pratt, 1981). Starr ve ark. (2015) 81 buğday çeşidi üzerine yaptıkları çalışmada toplamda 72 adet uçucu bileşenin mevcut olduğu ve bunların 17 tanesinin alkol grubuna, 14 tanesinin keton grubuna, 14 tanesinin aldehit grubuna, 9 tanesinin terpen grubuna, 6 tanesinin furan grubuna, 4 tanesinin ester grubuna, 4 tanesinin pirazin ve birer tane aromatik hidrokarbon, asit sülfür bileşiği ve amin grubuna ait olduklarını tespit etmişlerdir. Benzer şekilde, bazı araştırmacılarda buğday ve buğday türevlerinde aromatik bileşiklerin varlığını bildirmişlerdir. (Birch ve ark., 2013; Jensen ve ark., 2011; Maeda ve ark., 2009a; Maeda ve ark., 2009b; Bianci ve ark., 2008; Ruiz ve ark., 2003; Seitz ve ark., 1998; Hansen ve Hansen, 1994; Schierberle ve Grosch, 1991). Tarhana üretiminin son aşaması olan güneşte kurutma işleminde de günışığının etkisiyle farklı bileşikler oluşabilir. Günışığı protein, yağ, vitamin ve fenolik madde gibi birçok bileşene sahip tarhana hamurunda kimyasal tepkimeleri başlatır. Bradley (1980), sütün doğrudan günışığına maruz kalması sonucu proteinlerin parçalanarak amino asitlere dönüştüğünü, mevcut C-S bağlarının koptuğunu, yeni bileşiklerin oluştuğunu hatta mevcut sütte bulunan asetaldehit, propanal, metil sülfit, aseton, bütanone, $\mathrm{n}$-pentanal ve $\mathrm{n}$-hekzanal gibi bileşiklerin konsantrasyonlarında artış olacağını bildirmiştir. Benzer durum tarhananın kurutulması için de geçerli olabilir. 
Tablo 5. Örneklerdeki alkol-terpen grubu bileşiklerin listesi, miktarları (\% alan) ve istatistiksel sonuçları*

\begin{tabular}{|c|c|c|c|c|c|c|c|c|c|c|}
\hline \multirow{2}{*}{ 은 } & \multirow{2}{*}{ Bileşik } & \multicolumn{9}{|c|}{ Örnek } \\
\hline & & T1-3 & T1-6 & T1-9 & T2-3 & T2-6 & T2-9 & T3-3 & T3-6 & T3-9 \\
\hline \multirow{8}{*}{$\begin{array}{l}\overline{\underline{0}} \\
\frac{\mathrm{c}}{\alpha}\end{array}$} & 2,3 bütadiol & $\mathrm{TE}^{* *}$ & 1.71 & $\mathrm{TE}$ & $\mathrm{TE}$ & $\mathrm{TE}$ & TE & $\mathrm{TE}$ & $\mathrm{TE}$ & $\mathrm{TE}$ \\
\hline & Furfuril alkol & $0.41^{a x}$ & $0.95^{b x}$ & $1.31^{\mathrm{cr}}$ & $0.80^{\mathrm{aY}}$ & $1.08^{\mathrm{bx}}$ & $0.73^{a x}$ & $0.53^{a x}$ & $0.89^{b x}$ & $0.74^{a b x}$ \\
\hline & 2- etil heksanol & $0.37^{x}$ & TE & TE & $0.65^{Y}$ & $\mathrm{TE}$ & TE & TE & $\mathrm{TE}$ & 0.70 \\
\hline & Benzen etanol & $0.59^{a Y}$ & $0.85^{b}$ & $\mathrm{TE}$ & TE & $\mathrm{TE}$ & $\mathrm{TE}$ & $0.40^{x}$ & TE & TE \\
\hline & Okten-3-ol & TE & TE & $\mathrm{TE}$ & $\mathrm{TE}$ & $0.62^{x}$ & $\mathrm{TE}$ & TE & $0.67^{x}$ & TE \\
\hline & Benzil alkol & $\mathrm{TE}$ & $\mathrm{TE}$ & $\mathrm{TE}$ & TE & TE & $\mathrm{TE}$ & $0.88^{a}$ & $1.08^{b}$ & $\mathrm{TE}$ \\
\hline & 1-Bütanol & TE & TE & TE & 0.56 & TE & TE & TE & TE & TE \\
\hline & Heksanol & TE & TE & TE & $0.56^{b}$ & $0.25^{\mathrm{ax}}$ & $0.45^{b}$ & TE & $0.22^{x}$ & TE \\
\hline \multirow{3}{*}{$\begin{array}{l}\text { ¿ } \\
\text { 힌 }\end{array}$} & dl-limonen & $2.56^{\mathrm{bY}}$ & $1.72^{\mathrm{aY}}$ & $2.91^{\mathrm{bY}}$ & $2.41^{\mathrm{bY}}$ & $1.52^{\mathrm{aY}}$ & $1.75^{\mathrm{ax}}$ & $0.95^{\mathrm{ax}}$ & $1.09^{a b X}$ & $1.31^{\mathrm{bX}}$ \\
\hline & Karvakrol & $1.44^{\mathrm{a}}$ & $1.39^{\mathrm{a}}$ & TE & TE & TE & TE & TE & TE & TE \\
\hline & Simen & TE & TE & $\mathrm{TE}$ & $\mathrm{TE}$ & $\mathrm{TE}$ & $\mathrm{TE}$ & $\mathrm{TE}$ & $\mathrm{TE}$ & 0.11 \\
\hline
\end{tabular}

* “a-c" serisi bir kültürün üç farklı konsantrasyonları ve "X-Z" serisi üç farklı kültürün aynı konsantrasyonları arasındaki istatiksel farkı göstermektedir ( $p<0.05$ ).

** TE: tespit edilemedi.

Tablo 6. Örneklerdeki diğer bileşiklerin listesi, miktarları (\% alan) ve istatistiksel sonuçları*

\begin{tabular}{|c|c|c|c|c|c|c|c|c|c|}
\hline \multirow{2}{*}{ Bileşik } & \multicolumn{9}{|c|}{ Örnek } \\
\hline & T1-3 & $\mathrm{T} 1-6$ & T1-9 & T2-3 & T2-6 & T2-9 & T3-3 & T3-6 & T3-9 \\
\hline Dimetil disülfit & 0.22 & $\mathrm{TE}^{* *}$ & TE & $\mathrm{TE}$ & TE & TE & $\mathrm{TE}$ & TE & 0.08 \\
\hline Toluen & $3.31^{\mathrm{bz}}$ & $0.93^{\mathrm{ax}}$ & $1.42^{\mathrm{aY}}$ & $2.47^{\mathrm{aY}}$ & $3.77^{\mathrm{bz}}$ & $3.70^{\mathrm{bz}}$ & $0.43^{a x}$ & $1.72^{\mathrm{bY}}$ & $0.67^{a x}$ \\
\hline Etil benzen & 0.19 & $\mathrm{TE}$ & $\mathrm{TE}$ & TE & TE & TE & TE & 0.24 & TE \\
\hline O-ksilen & $0.28^{a x}$ & $\mathrm{TE}$ & 0.64 & $0.63^{b Y}$ & $0.67^{b}$ & $0.38^{a x}$ & TE & 0.69 & 0.41 \\
\hline Stiren & $5.44^{\mathrm{bXY}}$ & $4.12^{\mathrm{ax}}$ & $3.72^{\mathrm{ax}}$ & $6.13^{\mathrm{aY}}$ & 7.20 aY & $6.88^{\mathrm{aY}}$ & $4.09^{a x}$ & $\mathrm{TE}$ & $4.62^{a x}$ \\
\hline Asetil furan & TE & $0.32^{\mathrm{a}}$ & $0.41^{\mathrm{a}}$ & TE & TE & TE & TE & TE & TE \\
\hline 3,5-dimetil pirazin & TE & $0.55^{x}$ & TE & $0.53^{b x}$ & $0.54^{b x}$ & $0.28^{\mathrm{ax}}$ & $2.14^{\mathrm{bY}}$ & $1.53^{\mathrm{aY}}$ & $1.27^{\mathrm{aY}}$ \\
\hline 2-pentil furan & $5.04^{\mathrm{ax}}$ & $4.10^{\mathrm{ax}}$ & $4.48^{\mathrm{ax}}$ & $4.63^{\mathrm{ax}}$ & $5.92^{\mathrm{aY}}$ & $5.03^{a x}$ & $4.18^{a b x}$ & $4.03^{a x}$ & $5.18^{b x}$ \\
\hline Naftalin & $3.20^{\mathrm{b}}$ & $0.33^{a}$ & TE & TE & TE & TE & TE & TE & TE \\
\hline 2-metoksi 4-etenil fenol & TE & $0.55^{\mathrm{a}}$ & $0.41^{\mathrm{a}}$ & $0.61^{x}$ & $\mathrm{TE}$ & $\mathrm{TE}$ & $0.82^{x}$ & TE & $\mathrm{TE}$ \\
\hline p-dikloro benzen & TE & TE & TE & 0.50 & TE & $\mathrm{TE}$ & TE & TE & TE \\
\hline 3,5 dimetil fenol & $\mathrm{TE}$ & $\mathrm{TE}$ & $\mathrm{TE}$ & $0.63^{a x}$ & $0.97^{b x}$ & $\mathrm{TE}$ & $1.74^{\mathrm{aY}}$ & $1.64^{\mathrm{aY}}$ & $1.86^{\mathrm{a}}$ \\
\hline
\end{tabular}

* "a-c" serisi bir kültürün üç farklı konsantrasyonları ve "X-Z" serisi üç farklı kültürün aynı konsantrasyonları arasındaki istatiksel farkı göstermektedir ( $\mathrm{p<0.05).}$

** TE: tespit edilemedi. 


\section{Sonuç ve Öneriler}

Endüstriyel kültürler ile yapılan yoğurtlardan Maraş tarhanası üretimi gerçekleştirilmiştir. Tepe boşluğu analizi ile farklı oranlarda kullanılan farklı kültür çeşitlerinden üretilen tarhanaların uçucu bileşen çeşitleri ve miktarları belirlenmiştir. Aldehit grubu bileşik olan ve en yüksek miktarda bulunan furfural en çok YF-L903 kültürleri ile yapılan tarhanalarda görülmüş fakat kullanılan kültür miktarlarının etkisi istatiksel olarak önemsiz çıkmıştır. Bunun yanında en çok asit grubu bileşiklerini içermektedir. Ekşi tadı daha fazla seven tüketiciler için bu ürün tercih edilebilir. D-limonen bileşiği ürünlere hoş koku ve rahatlatıcı bir his veren terpendir. Limonen içeriği en yüksek olan tarhana \%9 oranında kullanılan YC-380 kültürden elde edilmiştir. YC-380 kültürü kullanılarak üretilen bütün tarhanaların uçucu bileşen sayısı diğerlerinden yüksek çıkmıştır. Bu çalışmada sadece uçucu bileşenler üzerine araştırma yapılmıştır. Sonraki çalışmalarda uçucu olmayan bileşikler üzerine araştırmalar yapılabilir ve duyusal karşılıkları ifade edilebilir.

\section{TEŞEKKÜR}

Bu çalışma KSÜ Bilimsel Araştırma Projeleri Birimi tarafından 2014/4-26D proje numarası ile desteklenmiştir.

\&: Bu makale "Farklı Kültürlerle Yapılan Yoğurtlardan Maraş Tarhanası Üretimi" adlı doktora tezinden üretilmiştir.

\section{Kaynaklar}

Belitz, H.D., Grosch, W., Schierberle, P. 2009. Food Chemistry. Springer UK, 340-343.

BeMiller, J.N., Pratt, G.V. 1981. Sorption of water, sodium sulfate, and water-soluble alcohols by starch granules in aqueous suspensions. Cereal Chemistry. 58: 517-520.

Bianchi, F., Careri, M., Chiavaro, E., Musci, M., Ve, E. 2008. Vittadini gas chromatographic-mass spectrometric characterisation of the Italian protected designation of origin "Altamura" bread volatile profile. Food Chemistry, 110: 787-793.

Birch, A.N., Petersen, M.A., Hansen, A. 2013. The aroma profile of wheat bread crumb influenced by yeast concentration and fermentation temperature. LWT-Food Science and Technology, 50: 480-488.

Bradley, Jr. R.L. 1980. Effect of light on alteration of nutritional value and flavor of milk: A review. Journal of Food Protection, 43(4): 314-320.

Coşkun, F. 2014. Tarhananın tarihi ve Türkiye'de tarhana çeşitleri. Gıda Teknolojileri Elektronik Dergisi, 9(3): 69-79.
Dağlıoğlu, O., Arıcı, M., Konyalı, M., Gümüş, T. 2002. Effects of tarhana fermentation and drying methods on the fate of Escherichia coli 0157:H7 and Staphylococcus aureus. European Food Research and Technology, 215(6): 515-519.

Eker, T., Cabaroğlu, T. 2018. Gıdaların tüketilmesi sırasında retronazal yolla aroma salınımının belirlenmesi. Gıda Dergisi, 43(1): 64-77.

Erbaş, M., Certel, M., Uslu, M.K. 2004. Yaş ve kuru tarhananın şeker içeriğine fermantasyon ve depolamanın etkisi. Gıda Dergisi, 29(4): 299305.

Erkaya, T., Şengül, M. 2008. Yoğurtta aroma bileşenleri. Hasad Gıda, 24(278): 32-37.

Gök, S.A., Ceyhun-Sezgin, A., Yıldırım, F. 2017. Gastronomi alanında Maraş tarhanasının değerlendirilmesi. Aydın Gastronomy, 1(1): 61-70.

Hansen, A., Hansen, B. 1994. Influence of wheat flour type on the production of flavour compounds in the wheat sourdoughs. Journal of Cereal Science, 19: 185-190.

Hau, M.Y.M., Gray, D.A., Taylor, A.J. 1996. Binding of Volatiles to Starch. "Alınmıştır: FlavorFood Interactions. (ed) McGorrin R.J. ve Leland J.V., American Chemical Society Symposium Series 633. ACS: Washington, DC, pp.109-117.

Jensen, S., Oestdal, H., Skibsted, L.H., Larsen, E., Thybo, A.K. 2011. Chemical changes in wheat pan bread during storage and how it affects the sensory perception of aroma, flavour, and taste. Journal of Cereal Science, 53: 259268.

Köse, Ş., Ocak, E. 2014. Yoğurtta Lezzet bilesenlerinin olusumu ve bu olusum üzerine etki eden faktörler. Akademik Gıda, 12(2): 101-107.

Leffingwell. 2018. VCF 2000-Volatile Compounds in Food DATABASE. http://www.leffingwell.com/bacis1.htm, (Access date: 14.12.2018).

Ligor, M., Wójcik, J., Buszewski, B. 2004. Application of the Solid Phase Microextraction (SPME) and gas chromatography (GS, GC/MS) in food analysis. Polish Journal of Food and Nutrition Sciences, 13(4): 355-362.

Maeda, T., Kim, J.H., Ubukata, Y., Morita, N. 2009a. Analysis of volatile compounds in polishedgraded wheat flour bread using headspace sorptive extraction. European Food Research and Technology, 228: 457-465.

Maeda, T., Kikuma, S., Araki, T., Ikeda, G., Takeya, K., Sagara, Y. 2009b. The effects of mixing stage and fermentation time on the quantity of flavor compounds and sensory intensity of 
flavor in white bread. Food Science and Technology Research, 15: 117-126.

McGee, D. 2003. ABD'de perakende zeytinyağı sektöründe pazarlama ve Türkiye'nin pazar payının arttırılmasına yönelik görüşler. Türkiye 1. Zeytinyağı ve Sofralık Zeytin Sempozyumu Bildirileri. 2/3 Ekim 2003. İzmir, s. 70-82.

Nijssen, L.M., Visscher, C.A., Maarse, H., Willemsens, L.C., Boelens, M.H. 1999. Volatile Compounds in Food. Qualitative and Quantitative Data. 7th Edition and supplements 1 and 2. TNO Nutrition and Food Research Institute, Zeist, Netherlands.

Nijssen, L.M., Ingen-Visscher, C.A., Van Donders, J.J.H. 2016. VCF Volatile Compounds in Food: Database Version 16.2. Zeist, the Netherlands: TNO Triskelion.

Özer, B. 2006. Yoğurt Bilimi ve Teknolojisi. Sidas Medya Ltd. Sti., Şanlıurfa, 488.

Özer, E.A. 2009. Ege Bölgesi ve Maraş yöresinde üretilen tarhanaların beslenmedeki yeri ve önemi. II. Geleneksel Gıdalar Sempozyumu, 27-29 Mayıs, Van, s.687-690.

Ruiz, J.A., Quilez, J., Mestres, M., Guasch, J. 2003. Solid-phase microextraction method for headspace analysis of volatile compounds in bread crumb. Cereal Chemistry, 80: 255-259.

Schierberle, P., Grosch, W. 1991. Potent odorants of the wheat bread crumb. Zeitschrift für Lebensmittel-Untersuchung und-Forschung, 192: 130-135.

Seitz, L.M., Chung, O.K., Rengarajan, R. 1998. Volatiles in selected commercial breads. Cereal Chemistry, 75: 847-853.

Starr, G., Petersen, M.A., Jespersen, B.M., Hansen, A.S. 2015. Variation of volatile compounds among wheat varieties and landraces. Food Chemistry, 174: 527-537.

Şekkeli, Z.H., Kaya, E., Erdem, T.K., Tekin, F.B. 2015. A research on determination of supply types of Maras tarhana at Kahramanmaras vocational school students. International Journal of Scientific and Technological Research, 1(2): 31-41. 